\title{
Efficacy and Safety of Adalimumab Biosimilars: Current Critical Clinical Data in Rheumatoid Arthritis
}

\author{
XiaoQin $\mathrm{Lu}^{1 \dagger}$, Rui Hu${ }^{2 \dagger}$, Lin Peng ${ }^{2}$, MengSi Liu ${ }^{2}$ and Zhen Sun ${ }^{2 *}$ \\ ${ }^{1}$ School of Pharmacy and Laboratory Science, Ya'an Polytechnic College, Ya'an, China, ${ }^{2}$ Hengyang Medical College, \\ University of South China, Hengyang, China
}

Adalimumab, as a TNF inhibitor biologic for the treatment of rheumatoid arthritis, is one of the top-selling drugs worldwide. As its various patents have gradually expired, experiments on its biosimilars are constantly being implemented. In this review, we summarized clinical trials of seven biosimilars currently approved by the FDA and/or EMA for the treatment of rheumatoid arthritis, namely: ABP 501 (Amjevita/Amgevita/Solymbic), Bl 695501 (Cyltezo), SB5 (Imraldi/Hadlima), GP2017 (Hyrimoz/Hefiya/Halimatoz), MSB11022 (Idacio), FKB327 (Hulio), and PF-06410293 (Abrilada). Overall, these biosimilars showed similar efficacy, safety, and immunogenicity

OPEN ACCESS

Edited by:

Linda L. Kusner,

George Washington University,

United States

Reviewed by:

Christian Fernandez,

University of Pittsburgh, United States

Fabiola Atzeni,

University of Messina, Italy

*Correspondence:

Zhen Sun

slzms@foxmail.com

${ }^{\dagger}$ These authors have contributed equally to this work

Specialty section:

This article was submitted to Autoimmune and Autoinflammatory

Disorders,

a section of the journa

Frontiers in Immunology

Received: 06 December 2020

Accepted: 23 February 2021

Published: 06 April 2021

Citation:

LuX, Hu R, Peng L, Liu M and Sun Z (2021) Efficacy and Safety of

Adalimumab Biosimilars: Current Critical Clinical Data in Rheumatoid Arthritis. Front. Immunol. 12:638444.

doi: 10.3389/fimmu.2021.638444 to adalimumab. All biosimilar switching trials indicated that switching from adalimumab to a biosimilar does not have a significant impact on efficacy, safety, and immunogenicity.

Keywords: adalimumab, biosimilar, rheumatoid arthritis, tumor necrosis factor- $\alpha$, efficacy, safety, immunogenicity

\section{INTRODUCTION}

Rheumatoid arthritis (RA) is a chronic, inflammatory joint disease, which can lead to severe joint damage and disability, therefore decreasing the patient's quality of life. With the promotion of scientific research and with a more in-depth understanding of RA, more choices and better development in therapies have been achieved (1). Biologic disease-modifying anti-rheumatic drugs, for example, have been a major advance in the treatment of patients with RA (2).

As a cytokine that is central to the inflammatory cascade, tumor necrosis factor-alpha (TNF- $\alpha$ ) regulates the immune response. Elevation of TNF- $\alpha$ levels have been observed in synovial fluid and the synovium of patients with RA $(3,4)$. It can lead to erosion of cartilage and bone destruction by inducing local inflammation and pannus formation and can then cause disability and loss of function. TNF- $\alpha$ inhibitors (TNFi), therefore, are indicated to treat moderately to severely active disease (5).

As the third TNFi approved by FDA, adalimumab (ADL) has shown excellent efficacy and safety and is widely used in clinical RA treatment (6). However, the long-term cost and high price is a primary defect (7). Therefore, the expected patent expiry of some of these therapeutics has stimulated interest in the development of biosimilars (8). A biosimilar is a biological medicine, that is similar, in terms of structure, function, and pharmacokinetics (PK), to another biological medicine that has previously been approved for use (9). Currently, seven ADL biosimilars are approved in the EU and/or the USA: ABP 501, BI 695501, SB5, GP2017, MSB11022, FKB327, and $\mathrm{PF}-06410293$, all of which have been proven to be similar in terms of safety and efficacy to the licensed reference product (RP) (Table 1$)^{1,2}$.

\footnotetext{
${ }^{1}$ Generics and Biosimilars Initiative (GaBI). Biosimilars Approved in Europe. Available online at: http://www.gabionline.net/ Biosimilars/General/Biosimilars-approved-in-Europe (accessed December 18, 2020).

${ }^{2}$ Generics and Biosimilars Initiative (GaBI). Biosimilars Approved in the US. Available online at: http://www.gabionline.net/ Biosimilars/General/Biosimilars-approved-in-the-US (accessed December 18, 2020).
} 
TABLE 1 | Approval status of adalimumab biosimilars.

\begin{tabular}{llcc}
\hline $\begin{array}{l}\text { Biosimilar } \\
\text { name }\end{array}$ & Brand name & $\begin{array}{c}\text { US FDA } \\
\text { (approval } \\
\text { status) }\end{array}$ & $\begin{array}{c}\text { EMA (approval } \\
\text { status) }\end{array}$ \\
\hline ABP 501 & Amjevita/Amgevita/Solymbic & 2016 & 2017 \\
Bl 695501 & Cyltezo & 2017 & 2017 \\
SB5 & Imraldi/Hadlima & 2019 & 2017 \\
GP2017 & Hyrimoz/Hefya/Halimatoz & 2018 & 2018 \\
MSB11022 & Idacio & - & 2019 \\
FKB 327 & Hulio & 2020 & 2018 \\
PF-06410293 Abrilada/Amsparity & 2019 & 2020 \\
\hline
\end{tabular}

There are, however, still subtle differences between the immunogenicity, efficacy, and safety of the seven biosimilars. There is currently a lack of head-to-head experiments comparing the differences between these biosimilars. Thus, this review aims to summarize the efficacy, safety, and immunogenicity of each biosimilar by reviewing the data from clinical trials, to provide a reference for clinicians to choose the most suitable biosimilar for different RA patients.

\section{RESULTS}

\section{ABP 501 (Amjevita/Amgevita/Solymbic)}

ABP 501 was the first ADL biosimilar to be approved by the FDA in 2016 and the EMA in 2017. In the preclinical study and phase I clinical trial, the function and PK was demonstrated to be similar between ABP 501 and ADL. In addition, the structural similarity that included general properties, primary and higherorder structure, carbohydrate structure, isoelectric profile, purity and impurities, and thermal-forced degradation profiles was also confirmed (10-12). The subsequent randomized, double-blind, phase III equivalence study was conducted in 526 patients with moderate to severe rheumatoid arthritis, despite methotrexate (MTX), to evaluate the safety, efficacy, and immunogenicity equivalence between ABP 501 and ADL (13).

The risk ratio of ACR2 0 at week 24 for the primary endpoint was 1.039 (90\% CI: 0.954-1.133; ABP501:74.6\%, ADL: 72.4\%), which was within the predefined equivalence margin of 0.738 to 1.355

Furthermore, the mean change of DAS28-CRP comparing the baseline in both the ABP501 and ADL groups was -2.32 , and the risk ratio for ACR50 and ACR70 was 0.948 (90\% CI: 0.819-1.097; ABP 501: 49.2\%, adalimumab: 52.0\%) and 1.130 (90\% CI: 0.872-1.464; ABP 501: 26.0\%, adalimumab: 22.9\%), further demonstrating the efficacy equivalence between ABP 501 and ADL.

\footnotetext{
Abbreviations: ADA, antidrug antibody; ADL, adalimumab; CPR, C reactive protein; ESR, erythrocyte sedimentation rate; ECL, electrochemiluminescence; FAS, full analysis set; ISR, injection site reaction; MSD, Meso scale discovery; MTX, methotrexate; OLE, open-label extension; PPS, per-protocol set; PK, pharmacokinetic; RP, reference product; SAE, severe adverse event; SAF, safety analysis set; TEAE, treatment-emergent adverse event; ACR, American College of Rheumatology; 20, 50 or $70 \%$ improvement in the ACR core set measurements; DAS28, 28-joint disease Activity Score; DAS28 is considered positive when remission <2.6; EULAR, European league against rheumatism criteria (based on changes in DAS28).
}

The subsequent open-label extension (OLE) study evaluated the long-term safety and efficacy of APB 501 for rheumatoid arthritis patients, which included 467 patients who completed the parent study. At week 24, patients in the ABP 501 group continued with ABP501 (ABP501/ABP501) and patients in the ADL group transitioned to ABP 501(ADL/ABP 501). The ACR20 rates at week 48 and 70 were 77.6 and $78.8 \%$, respectively. The ACR20 rates in the ABP 501/ABP 501 group and ADL/ABP 501 group were still comparable (14).

The treatment-emergent adverse events (TEAEs) rate of ABP 501 and ADL in the parent study was similar (50.0 and $54.6 \%$, respectively), in which the percentage of patients with severe adverse events (SAEs) was also similar (3.8 vs. 5.0\%, respectively). One malignant tumor was found in each group and no active tuberculosis was reported (13). In the OLE study, all the proportions of TEAEs (62.4 vs. $65.0 \%$, respectively) and SAEs (10.9 vs. $8.9 \%$, respectively) that occurred in the ABP 501/ABP 501 and ADL/ABP 501 group were similar (14). The most common adverse event in the short and long-term was infection. No fatal events were reported.

Antidrug antibody (ADA) status and neutralizing antibodies (nAbs) were assessed by a highly sensitive and drug tolerant assay based on the Meso Scale Discovery (MSD) electrochemiluminescence (ECL) platform and a cell-based bioassay using a TNF $\alpha$-responding cell line that results in a $\mathrm{TNF} \alpha$-induced phosphorylation of nuclear factor $\kappa \mathrm{B}$, respectively (12). The percentage of patients with ABP 501 and the ADL groups that tested positive for binding ADAs (38.3 vs. $38.2 \%$, respectively) and nAbs (9.1 vs. $11.1 \%$, respectively) were similar. Of note, the percentage of ACR20 responders throughout the parent study was similar between the treatment groups despite ADA status (13). In the subsequent OLE study, the ADAs and nAbs were relatively increased, and the positive rate between those continuing on the ABP 501 group and those transitioning from $\mathrm{ADL}$ to the $\mathrm{ABP} 501$ group remained similar (14).

\section{BI 695501 (Cyltezo)}

BI 695501 was approved by the EMA and FDA in 2017. Previous research has confirmed its similarity in structure, function, and PK to $\operatorname{ADL}(15,16)$.

A randomized, double-blind, parallel-arm, 58-week trial was conducted by Cohen et al. to demonstrate the clinical equivalence of BI 695501 with ADL. Six-hundred-and-forty-five patients with moderate-to-severe RA in this trial were all on stable MTX (15-25 mg/week background treatment for $\geq 12$ weeks before enrolment and 10-14 mg/week was also permitted if patients were intolerant to larger dose). Patients were randomized 1:1 to receive $40 \mathrm{mg}$ of $\mathrm{BI} 695501(n=324)$ or $\mathrm{ADL}(n=321)$ subcutaneously, once every 2 weeks for 24 weeks. At week 24, patients were re-randomized to continue with the initial drugs or to switch from ADL to BI 695501(BI695501/BI695501, ADL/ADL and ADL/BI695501) (16).

Co-primary efficacy endpoints were ACR20 response at week 12 (requested by the FDA) and at week 24 (requested by the EMA), based on FAS. At week 12, 67.0 and $61.1 \%$ of patients in the BI 695501 group and ADL group achieved ACR20, respectively. The difference $(5.9 \% ; 90 \% \mathrm{CI}-0.9$ to 12.7$)$ was 
within pre-specified margins set by the FDA to demonstrate equivalence: -12 and $15 \%$. At week 24, 69.0 and $64.5 \%$ patients in the BI 695501 group and ADL group achieved ACR20, respectively. This difference $(4.5 \%, 95 \% \mathrm{CI}-3.4$ to 12.5$)$ was within -15 and $15 \%$ set by the EMA. The difference between BI 695501 and ADL was $4.3 \%(90 \% \mathrm{CI}-2.8$ to 11.3$)$ at week 12 and $1.6 \%(90 \%$ CI -5.3 to 8.5$)$ at week 24 , if based on the PPS. Secondary endpoints (ACR50, ACR70, EULAR responses, DAS28 and SF-36) were also reported to be similar at week 24. ACR20/50/70, DAS28-ESR, and EULAR were comparable at week 48, and no significant differences were reported, as well (16).

The safety analysis set (SAF) included all patients who received at least one dose of the trial drug. Again, overall safety was similar between the treatment groups. Up to week 58 , patients with at least one TEAE were 193 (59.6\%) in BI695501/BI695501, 93 (63.7\%) in ADL/BI695501, and 105 (60.0\%) in ADL/ADL. Among them, patients with at least one drug-related TEAE were BI695501/BI695501: 62 (19.1\%), ADL/BI695501: 28 (19.2\%) and ADL/ADL: 40 (22.9\%). Among all TEAEs, infections and infestations were the most common organ class system: $35.2 \%$ (114/324) for continuous BI 695501 group vs. $34.3 \%(60 / 175)$ for continuous ADL. Up to week 24 , serious infections all occurred in the ADL group: four had pneumonia, two had acute pyelonephritis, one had infective arthritis, one had appendicitis, and one had bronchitis. Cellulitis was reported in one patient in the BI 695501 group. From week 24 to week 58 , in terms of serious infections, there was one patient with pneumonia in the ADL/ADL group, and one patient with influenza, viral pneumonia, and salmonella sepsis in the ADL/BI 695501 group. No deaths were reported (16).

ADA status was detected by a single bridging ECL assay based on the MSD platform with an acid dissociation step and nAbs was measured by a cell-based antibody-dependent cell-mediated cytotoxicity method. The comparable occurrence rates of patients developing ADA were $47.4 \%$ in the BI 695501 group and $53.0 \%$ in the ADL group, up to week 24. And this trial showed that nAbs frequencies between the BI 695501 and ADL group were also similar at week 24. Whether ADA or nAbs, they occurred in all three treatment groups at similar rates up to week 48 , since the re-randomizing at week 24 (16).

\section{SB5 (Imraldi/Hadlima)}

SB5 was approved by the EMA and FDA in 2017 and 2019, respectively, and was proven to have s similar structure, function, and PK to ADL $(17,18)$. Weinblatt et al. $(17,19)$ phase III, randomized, double-blind, parallel group study comparing SB5 with ADL in efficacy, safety, and immunogenicity included 544 moderate to severe RA patients, despite MTX treatment. In this trial, all patients were biologic naive previously. Patients were randomized 1:1 to receive $40 \mathrm{mg}$ SB5 or ADL subcutaneously every other week for 24 weeks. At week 24, patients receiving ADL were randomized to SB5 or ADL until week 52, and patients on SB5 continued with SB5 $(17,19)$.

The primary efficacy endpoint was ACR20 response at week 24 in the per-protocol set (PPS; completer analysis). Results showed that the SB5 group and ADL group achieved comparable ACR20 response rates ( 72.4 and $72.2 \%$, respectively), and the rate difference was $0.1 \%$ (95\% CI, -7.83 to $8.13 \%$ ). A similar ACR20 response was also observed in the full analysis set (FAS): $68.0 \%$ for the SB5 group and $67.4 \%$ for the ADL group. The rate difference was $0.8 \%$ (95\% CI, -7.03 to $8.56 \%$ ) for the FAS. The difference in both PPS and FAS were within the predefined equivalence margin ( -15 to $15 \%$ ). The ACR50 and ACR70 response rates at week 24 were equivalent and the mean change from baseline to week 24 in the DAS28-ESR scores was also comparable for SB5 and ADL $(-2.74,-2.68$, respectively). Other secondary efficacy endpoints were all comparable according to the results (17). A subsequent transition study showed an equivalent ACR response at week 52 in the SB5/SB5, $\mathrm{ADL} / \mathrm{SB} 5$, and $\mathrm{ADL} / \mathrm{ADL}$ group, indicating that a transition from ADL to SB5 did not affect the efficacy and the long-term efficacy of SB5 (19).

TEAEs occurred in $35.8 \%$ of patients in the SB5 group and in $40.7 \%$ of patients in the ADL group by week 24 . Among them, 10.1 and $11.7 \%$ of patients were considered related to the study drug, respectively. $1.1 \%$ patients in the SB5 group and $2.9 \%$ patients in the ADL group were reported to have serious TEAEs. One $(0.4 \%)$ patient in the SB5 group (Escherichia urinary tract infection) and two (0.7\%) patients in the ADL group (bronchopneumonia and staphylococcal sepsis) presented serious infections. The proportion of patients reported to have injection site reactions was similar between the SB5 and ADL group. Two patients in the ADL group experienced malignancy (lymphoma and metastases to spine, papillary thyroid cancer). Two deaths occurred up to week 24 and were not considered to be related to the study drug (17). The safety was also comparable between the SB5/SB5, ADL/SB5, and ADL/ADL groups after switching at week 24: the proportion of any TEAMs was 32.3, 37.6 , and $33.1 \%$, respectively (19).

ADA status was determined using MSD ECL bridging, applying an SB5 single tagged immunoassay. At week 24, the incidence of ADA was similar for the SB5 and ADL groups (33.1 and $32.0 \%$, respectively). $32.4 \%(80 / 247)$ and $31.4 \%(82 / 261)$ of patients were reported to have emergent ADAs in the SB5 group and ADL group. And the proportion of boosted Abs was $42.1 \%$ $(8 / 19)$ and $50 \%(4 / 8)$, respectively. In both treatment groups, about half of all the antibodies were found to be neutralizing. The incidence at week 52 was also comparable after switching: $15.7 \%$ (40/254), $16.8 \%(21 / 125)$, and $18.3 \%(23 / 126)$ in the SB5/SB5, $\mathrm{ADL} / \mathrm{SB} 5$, and ADL/ADL groups, respectively $(17,19)$.

\section{GP2017 (Hyrimoz/Hefya/Halimatoz)}

GP2017 was approved by the FDA and EMA in 2018. Previous studies demonstrated that GP2017 and Humira have identical amino acid sequences, indistinguishable secondary and tertiary structures, the same level of post-translational modifications, and a functional and pharmacological similarity to the reference drug $(20,21)$. Wiland et al. $(22,23)$ conducted a phase III trial including 353 moderate-to-severe RA patients with inadequate response to disease modifying anti-rheumatic drugs. Patients were on a stable dose of MTX with biologics. At week 24, the patients in the ADL group were switched to receive GP 2017 up to week $46(22,23)$.

The primary endpoint mean change of DAS28-CRP from baseline to week 12 was -2.16 in the GP2017 group and 
-2.18 in the ADL group $(\mathrm{RD}=0.02 ; 95 \% \mathrm{CI}:-0.24,0.27)$. The mean change of DAS28-CRP from baseline to week 48 in the FAS population was -2.92 and -2.74 in the ADL /GP2017, and GP2017/GP2017 groups, respectively. In addition, the ACR20/50/70 responses of the two groups were also similar before and after switching, throughout the trial $(22,23)$.

Respectively, 61.6 and $60.2 \%$ of patients in the GP2017 and ADL groups presented with TEAEs and the most common TEAE was infections and infestations. During the switch period, the incidence of TEAEs were 32.5 and $36.5 \%$ in the ADL /GP2017 and GP2017/GP2017 groups, respectively. The incidence of SAEs was low and remained comparable in both groups during the entire study (ADL /GP2017: 5.7\%; GP2017/GP2017: 4.0\%), and no deaths occurred $(22,23)$.

A validated competitive ligand-binding assay and an ECL bridging immunogenicity assay were used to assess the incidence of ADAs. ADAs tested positive in 24.2 and $25.6 \%$ of patients in the GP2017/continued and ADL/switched group, respectively, of which more than $70 \%$ in both groups had a positive nAbs. After switching, 26.3 and $24.0 \%$ of patients tested positive for ADAs in the ADL/switched and GP2017/continued groups, respectively. No statistical differences were observed. The ADA status did not have a clinically significant impact on safety $(22,23)$.

\section{MSB11022 (Idacio)}

MSB11022 was approved by the EMA in 2019. Preclinical studies have proven its structural and functional similarities to the reference drug, which included the same amino acid sequence, $\mathrm{N}$-/C-terminal modifications, the relative distribution of the intact and glycated forms of both light chain and heavy chain, as well as C-terminal lysine truncation of a heavy chain level of MBS11022. Lower oxidation levels showed in MSB11022 compared to ADL. There was also no difference in the high-order structure (24). A phase I trial conducted in healthy subjects has demonstrated bioequivalence with the reference drug in terms of PK, safety, tolerability, and immunogenicity (25). Edwards et al. (26) conducted a phase III randomized, double blind parallel group, 52-week trial which included 288 patients with moderately-to-severely active RA on stable MTX treatment with an inadequate response. The phase III trial consisted of a 4 -week screening period, a 52-week double-blind treatment period, and a 4-month safety follow-up period (26).

The ACR20 response rates at week 12 for the ITT population were 79.6 and $80.9 \%$ for MSB11022 and ADL, respectively. The $95 \%$ CI for treatment difference was -10.55 to 8.04 , which demonstrated the similarity between the biosimilar and reference product. The similarity persisted up to week 52 . The proportion of patients achieving ACR50 and ACR70, DAS28- ESR scores, SDAI, and CDAI scores were also similar between the two treatments throughout the trial (26).

By week 52, the percentage of TEAEs was similar between the MSB11022 group and ADL group (58.0 vs. $64.1 \%$, respectively), while compared with the $\mathrm{ADL}$ group, patients in the MSB11022 group had a lower rate of permanent discontinuation due to TEAEs (4.2 vs. 9.7\%). In addition, compared with the reference product, MSB11022 also showed a trend toward reduced incidence of serious TEAEs (9.7 vs. $4.9 \%$, respectively) and treatment-related TEAEs (40 vs. $21.7 \%$, respectively). Hypersensitivity, the primary endpoint of the trial occurred in similar proportions and types in both the MSB1022 and ADL groups (4.2 vs. 5.5\%, respectively). There were fewer injection site reactions (ISRs) in the MSB11022 group than in the ADL group (9.1 vs. $22.8 \%$, respectively). These differences were not considered notable (26).

An ECL bioanalytical method based on the MSD platform was used to detect the ADA status. Respectively, 80.4 and $71.7 \%$ of patients in the MSB11022 and ADL groups had at least one positive ADA result, of which $39.9 \%$ in the MSB11022 group and $39.3 \%$ in $\mathrm{ADL}$ group had a positive $\mathrm{nAb}$ result. Of note, The ADA-positive patients were observed to have a lower mean trough concentration than the ADA-negative patients, but no differences in efficacy and safety were reported (26).

Although switching treatment between MSB11022 and RP is not currently performed in RA patients, the switching effects have been evaluated in patients with psoriasis. In the phase III AURIEL-PsO trial, Psoriasis patients with a more than $50 \%$ improvement in the Psoriasis Area and Severity Index in the RP treatment group were rerandomized 1:1 to continue $\mathrm{RF}$ or to switch to MSB11022. Their results showed that the time to reach PASI 75, 90, and 100 and Physician's Global Assessment improvements in the three treatment groups at week 24 and 52 were comparable. The safety endpoints were also similar across the three groups, including serious adverse events, treatment-related TEAEs, and treatment discontinuations due to TEAEs. The incidences of a positive ADA result in the RP/RP, MSB11022/MSB11022, and RP/MSB11022 group were 92.1, 93.2, and $94.1 \%$, respectively, and about $60 \%$ of patients were $\mathrm{nAD}$ positive, which did not show statistical difference. In addition, the PK results were comparable after switching. In conclusion, the trial found that switching did not affect the endpoints of interest in psoriasis patients, which provides supporting evidence for its use in RA patients (27).

Currently, MSB11022 has two formulations: one is a citrate buffer, the other is an acetate buffer. The phase III trial only studied the acetate-buffered formulation, but an additional study demonstrated bioequivalence and a similar safety and immunogenicity profile between two formulations in healthy subjects (EMR200588-003).

\section{FKB327 (Hulio)}

FKB327 was approved by the EMA and FDA in 2018 and 2020, respectively. A preclinical trial has demonstrated its structural and functional similarity to ADL. A subsequent phase I trial has demonstrated similarities in PK and safety in healthy subjects $(28)^{3}$. Genovese et al. conducted a randomized, phase III, doubleblind study, and its open-label extension, which enrolled 730 active rheumatoid arthritis patients aged $\geq 18$ years on a stable

\footnotetext{
${ }^{3}$ European Medicines Agency. Human Medicine European Public Assessment Report: Hulio. Available online at: https://www.ema.europa.eu/en/documents/ass essment-report/hulio-epar-public-assessment-report_en.pdf (accessed November $25,2020)$.
} 
dose of MTX. In this trail, patients were randomized 1:1 to receive FKB327 or RP for 24 weeks in period 1, and then the completed patients were randomized 2:1 according to the original group, two-thirds of which continued the same treatment, and one-third of which switched until week 54 in period 2, and then a double switch was performed in the FKB327 to the ADL group and the continuing ADL group was switched to FKB327 in period $3(29,30)$.

The primary efficacy endpoint was the treatment difference of ACR20 at week 24 between the FKB327 and ADL groups, and its $95 \%$ CI was -7.9 to 4.7 (FKB327: 74.1\%, ADL: $75.7 \%$ ) and the $95 \% \mathrm{CI}$ of the least squares mean DAS28-CRP difference at the same time was -0.16 to 0.18 (FKB327: 3.43, RP: 3.42), all of which were within the predefined equivalence margin and all of which demonstrated their efficacy similarity. In addition, the percentages of patients achieving ACR50 and ACR70 were comparable for the two treatments throughout period 1, and the subgroup analyses were performed by geographic region, DAS28-CRP concentration, and prior biologic medication for RA, which did not show differences among these subgroups. The subsequent OLE trial also indicated similar increases in ACR20, ACR50, or ACR70 response rates and decreases in mean DAS28CRP in four treatment groups at all visits, which demonstrated that the efficacy was not affected by switching treatments. The efficacy tended to increase over time throughout the trial $(29,30)$.

The treatment-emergent adverse events (TEAEs) were similar, with more than $60 \%$ in period 1 and period 2 , and the longterm TEAEs was also comparable in patients treated with FKB327 and patients treated with the RP (1.707 vs. 2.075 events per patient-year, respectively). The treatment-emergent serious AEs were also similar but the percentage of treatment-emergent SAEs resulting in discontinuation were relatively higher for FKB327 than for RP ( 0.025 vs. 0.011 events per patient-year, respectively). The most common TEAEs were nasopharyngitis and other infections. Of note, latent TB was reported to be one of the most common adverse events, but it was thought to be the result of the included population, which included patients from counties with general high TB rates. The ISR rates in all of groups were low and comparable. The incidences of malignancy or death were low, and each group was balanced without meaningful differences $(29,30)$.

ADA status was determined using the ECL bridging format based on MSD and an acid dissociation was introduced. A sensitive competitive ligand binding method was used to detect nAbs. The percentage of ADA-positive patients at week 24 was $57.9 \%$ in the FKB327 group and 55.5\% in the RP group, in which almost all patients were neutralizing ADAs. At week 54, the percentage of RP/RP, FKB327/FKB327, RP/FKB327, and FKB327/RP groups were 51.6, 52.2, 45.2, and 61.0\% respectively, with most of them remaining with neutralizing ADAs. The slight differences across all treatment groups were deemed to be associated with the smaller number of patients in each group after re-randomization. The percentage of patients who tested positive for $\mathrm{ADAs}$ and titer level in all treatment groups were comparable (29).

\section{PF-06410293 (Abrilada, Amsparity)}

PF-06410293 was approved by the FDA and EMA in 2019 and 2020, respectively. Peptide mapping analysis showed that PF06410293 and ADL had identical amino acid sequences (31). Efficacy, safety, tolerability, and immunogenicity profiles of PF06410293 have also been proven to be similar to ADL in previous studies $(31,32)$.

A double-blind, randomized, study evaluating the efficacy, safety, immunogenicity, PK, and pharmacodynamics of PF06410293597 vs. ADL was conducted by Fleischmann et al. Eligible RA patients were randomized 1:1 to receive $40 \mathrm{mg}$ PF-06410293 $(n=297)$ or ADL $(n=300)$ once every 2 weeks. Patients were on a stable dose of MTX with biologics. At week 26, treatment period 2 was started, patients receiving ADL were re-randomized 1:1 to receive PF-06410293 or to continue with ADL for 26 weeks, while patients in the PF-06410293 group remained on the PF-06410293 treatment (33).

The primary endpoint was ACR20 response at week 12. At week 12,68.7\% (204/297) of patients in the PF-06410293 group and $72.7 \%(218 / 300)$ patients in the ADL group achieved ACR20, and the difference was $-3.98 \%$. With non-responder imputation, the treatment difference at week 12 in ACR20 (-2.98\%; 95\%CI -10.38 to 4.44 and $90 \% \mathrm{CI}-9.25$ to $3.28 \%$ ) was within the pre-specified margins ( $95 \% \mathrm{CI} \pm 14 \%$ and $90 \% \mathrm{CI}-12$ to $15 \%)$ demonstrating equivalence between PF-06410293 and ADL. This study also showed similar ACR20 results between PF-06410293 and ADL in the PPS (71.1 vs. 75.2\%). Secondary endpoints were also comparable between treatment groups at week 12 (33). In treatment period 2, ACR2 0 and other endpoints remained similar between the treatment groups (34).

In treatment period 1 , the proportions of patients with at least one TEAE were similar: $48.1 \%$ (143/297) in the PF06410293 group and $47.8 \%(143 / 299)$ in the ADL group. The most frequently reported TEAEs were increased alanine aminotransferase, viral upper respiratory tract infections, hypertension, and headaches. No active TB occurred. SAEs were 4.0 and $4.3 \%$ in the PF-06410293 and ADL group, respectively. The system organ classes with the highest proportion of patients with SAEs were infestations and infections, which occurred in three patients in each treatment group. The incidence of injection-site reactions (1.7 and 2.0\%) and opportunistic infections (2.4 and 1.7\%) was similar between treatment groups (33). In treatment period 2, after switching at week 26, adverse events occurred at $43.5 \%(123 / 243)$ in the PF-06410293/PF06410293 group, $44.4 \%$ (60/112) in ADL/ADL group, and $38.3 \%$ $(51 / 100)$ in ADL/ PF-06410293 group. Other results were also similar (34).

A single validated ECL immunoassay was used to determine the ADA status, and then the ADA-positive patients were further tested for nAbs activity with a validated cell-based assay using PF-06410293 as the capture agent. Overall, 44.4 and 50.5\% of patients in the PF-06410293 and ADL group tested positive for ADA at least once, respectively, and 13.8 and $14.0 \%$ of patients developed nAbs in the PF-06410293 and ADL group, respectively (33). Incidences of ADA through week 52 were also comparable 
TABLE 2 | The summary of characteristic and key endpoints of each pivotal trial.

\begin{tabular}{|c|c|c|c|c|c|c|c|c|c|c|}
\hline $\begin{array}{l}\text { Biosimilar } \\
\text { name }\end{array}$ & Patients & $\begin{array}{l}\text { Time of } \\
\text { treatment }^{\dagger}\end{array}$ & $\begin{array}{l}\text { Incidence of } \\
\text { TEAEs vs. ADL }\end{array}$ & RR $(95 \% \mathrm{Cl})$ & $\begin{array}{l}\text { Primary efficacy } \\
\text { endpoint vs. ADL }\end{array}$ & RR $(95 \% \mathrm{Cl})$ & $\begin{array}{l}\text { ACR70 response } \\
\text { vs. } A D L\end{array}$ & RR (95\%Cl) & $\begin{array}{l}\text { Incidence of } \\
\text { ADAs vs. ADL }\end{array}$ & RR (95\%Cl) \\
\hline $\begin{array}{l}\text { ABP } 501 \\
\text { (NCT01970475) } \\
\text { (NCT02114931) }\end{array}$ & $\begin{array}{l}\text { 18-80 years old } \\
\text { with moderate to } \\
\text { severe active RA } \\
\text { despite MTX }\end{array}$ & 68 weeks & $\begin{array}{l}50.0 \text { vs. } 54.6 \% \text { up } \\
\text { to week } 26\end{array}$ & $\begin{array}{c}0.92 \\
(0.78-1.08)\end{array}$ & $\begin{array}{l}\text { ACR20: } 74.6 \text { vs. } \\
72.4 \% \text { at week } 24\end{array}$ & $\begin{array}{c}1.03 \\
(0.93-1.14)\end{array}$ & $\begin{array}{l}26.0 \text { vs. } 22.9 \% \text { at } \\
\text { week } 24\end{array}$ & $\begin{array}{c}1.14 \\
(0.83-1.55)\end{array}$ & $\begin{array}{l}38.3 \text { vs. } 38.2 \% \text { up } \\
\text { to week } 26\end{array}$ & $\begin{array}{c}1.00 \\
(0.81-1.25)\end{array}$ \\
\hline $\begin{array}{l}\text { Bl } 695501 \\
\text { (NCT02137226) } \\
\text { (NCT02640612) }\end{array}$ & $\begin{array}{l}\text { 18-80 years old } \\
\text { with moderate to } \\
\text { severe active RA } \\
\text { despite MTX }\end{array}$ & 98 weeks & $\begin{array}{l}59.6 \text { vs. } 60.0 \% \text { up } \\
\text { to week } 58\end{array}$ & $\begin{array}{c}0.99 \\
(0.85-1.15)\end{array}$ & $\begin{array}{l}\text { ACR20: } 67.0 \text { vs. } 61.1 \% \\
\text { at week } 12,69.0 \% \text { vs. } \\
64.5 \% \text { at week } 24\end{array}$ & $\begin{array}{c}1.10 \\
(0.98-1.23) \\
1.07 \\
(0.96-1.19)\end{array}$ & $\begin{array}{l}10.0 \text { vs. } 11.0 \% \text { at } \\
\text { week } 12,13.4 \text { vs. } \\
18.2 \% \text { at week } 24\end{array}$ & $\begin{array}{c}0.91 \\
(0.58-1.43) \\
0.73 \\
(0.51-1.06)\end{array}$ & $\begin{array}{l}47.7 \text { vs. } 53.0 \% \text { up } \\
\text { to week } 24\end{array}$ & $\begin{array}{c}0.90 \\
(0.76-1.05)\end{array}$ \\
\hline $\begin{array}{l}\text { SB5 } \\
\text { (NCT02167139) }\end{array}$ & $\begin{array}{l}\text { 18-75 years old } \\
\text { with moderate to } \\
\text { severe active RA } \\
\text { despite MTX }\end{array}$ & 52 weeks & $\begin{array}{l}35.8 \text { vs. } 40.7 \% \text { up } \\
\text { to week } 24\end{array}$ & $\begin{array}{c}0.88 \\
(0.71-1.09)\end{array}$ & $\begin{array}{l}\text { ACR20: } 72.4 \text { vs. } \\
72.2 \% \text { at week } 24\end{array}$ & $\begin{array}{c}1.00 \\
(0.90-1.12)\end{array}$ & $\begin{array}{l}19.2 \text { vs. } 20.3 \% \text { at } \\
\text { week } 24\end{array}$ & $\begin{array}{c}0.95 \\
(0.66-1.37)\end{array}$ & $\begin{array}{l}33.1 \text { vs. } 32.0 \% \text { up } \\
\text { to week } 24\end{array}$ & $\begin{array}{c}1.03 \\
(0.80-1.33)\end{array}$ \\
\hline $\begin{array}{l}\text { GP2017 } \\
\text { (NCT02744755) }\end{array}$ & $\begin{array}{l}\geq 18 \text { years old with } \\
\text { moderate to } \\
\text { severe active RA } \\
\text { despite MTX }\end{array}$ & 46 weeks & $\begin{array}{l}61.6 \text { vs. } 60.2 \% \text { up } \\
\text { to week } 24\end{array}$ & $\begin{array}{c}1.02 \\
(0.87-1.21)\end{array}$ & $\begin{array}{l}\text { DAS28-CRP: }-2.16 \\
\text { vs. }-2.18 \text { at week } 12 \\
\text { ACR20: } 82.4 \text { vs. } \\
78.6 \% \text { at week } 12\end{array}$ & $\begin{array}{c}0.02^{*} \\
(-0.24 \text { to } 0.27) \\
1.05 \\
(1.92-1.19)\end{array}$ & $\begin{array}{l}21.3 \text { vs. } 26.2 \% \text { at } \\
\text { week } 12\end{array}$ & $\begin{array}{c}0.81 \\
(0.51-1.30)\end{array}$ & NP & NA \\
\hline $\begin{array}{l}\text { MSB11022 } \\
\text { (NCT03052322) }\end{array}$ & $\begin{array}{l}\geq 18 \text { years of age } \\
\text { with moderate to } \\
\text { severe active RA } \\
\text { despite MTX }\end{array}$ & 48 weeks & $\begin{array}{l}58.0 \text { vs. } 64.1 \% \text { up } \\
\text { to week } 52\end{array}$ & $\begin{array}{c}0.90 \\
(0.75-1.10)\end{array}$ & $\begin{array}{l}\text { ACR20: } 79.6 \text { vs. } \\
80.9 \% \text { at week } 12\end{array}$ & $\begin{array}{c}0.98 \\
(0.88-1.11)\end{array}$ & $\begin{array}{l}27.3 \text { vs. } 20.0 \% \text { at } \\
\text { week } 12\end{array}$ & $\begin{array}{c}1.36 \\
(0.89-2.08)\end{array}$ & $\begin{array}{l}80.4 \text { vs. } 71.7 \% \text { up } \\
\text { to week } 52\end{array}$ & NA \\
\hline $\begin{array}{l}\text { FKB327 } \\
\text { (NCT02260791) } \\
\text { (NCT02405780) }\end{array}$ & $\begin{array}{l}\geq 18 \text { years of age } \\
\text { with moderate to } \\
\text { severe active RA } \\
\text { despite MTX }\end{array}$ & 100 weeks & $\begin{array}{l}62.2 \text { vs. } 66.2 \% \text { up } \\
\text { to week } 54\end{array}$ & $\begin{array}{c}0.94 \\
(0.85-1.03)\end{array}$ & $\begin{array}{l}\text { ACR20: } 74.1 \text { vs. } \\
75.7 \% \text { at week } 24\end{array}$ & $\begin{array}{c}0.98 \\
(0.90-1.07)\end{array}$ & $\begin{array}{l}21.3 \text { vs. } 25.1 \% \text { at } \\
\text { week } 24\end{array}$ & $\begin{array}{c}0.84 \\
(0.65-1.10)\end{array}$ & $\begin{array}{l}57.9 \text { vs. } 55.5 \% \text { up } \\
\text { to week } 24\end{array}$ & $\begin{array}{c}1.04 \\
(0.92-1.18)\end{array}$ \\
\hline $\begin{array}{l}\text { PF-06410293 } \\
\text { (NCT02480153) }\end{array}$ & $\begin{array}{l}\geq 18 \text { years of age } \\
\text { with active RA } \\
\text { despite MTX }\end{array}$ & 78 weeks & $\begin{array}{l}48.1 \text { vs. } 47.8 \% \text { up } \\
\text { to week } 26\end{array}$ & $\begin{array}{c}1.01 \\
(0.85-1.19)\end{array}$ & $\begin{array}{l}\text { ACR20: } 68.7 \text { vs. } \\
72.7 \% \text { at week } 12\end{array}$ & $\begin{array}{c}0.95 \\
(0.85-1.05)\end{array}$ & $\begin{array}{l}16.5 \text { vs. } 19.0 \% \text { at } \\
\text { week } 12\end{array}$ & $\begin{array}{c}0.87 \\
(0.61-1.23)\end{array}$ & $\begin{array}{l}44.4 \text { vs. } 50.5 \% \text { up } \\
\text { to week } 26\end{array}$ & $\begin{array}{c}0.88 \\
(0.74-1.04)\end{array}$ \\
\hline
\end{tabular}

${ }^{\dagger}$ Time of treatment included the last time the patients in the open label extension trial received the test drug. ${ }^{*}$ mean difference.

RR, risk ratio; TEAES, treatment-emergent adverse events; ADL, adalimumab; ADAs, anti-drug antibodies; NP, not provided; NA, not available (because of the lack of data cannot be calculated). 
between treatment groups with $47.3,54.1$, and $45.9 \%$ for the PF-06410293/PF-06410293, ADL/ADL, and ADL/ PF-06410293 group, respectively (34).

\section{DISCUSSION}

Each clinical trial showed that currently approved ADL biosimilars and RP had similar endpoints, including in the switching treatment performed (Table 2) (Figure 1). In clinical practice, to switch from ADL to a biosimilar, it must be based on a shared decision between the patients and the prescribing physician, and post-marketing safety analyses. It is worth noting that if a biosimilar gets the "interchangeability" designation allowed by the FDA, the biosimilar could be automatically substituted at the pharmacy level without consulting the prescribing physician (35). This designation can be applied only if the manufacturer is able to provide sufficient evidence that "the risk in terms of safety or diminished efficacy of alternating or switching between use of the biological product (biosimilar) and the RP is not greater than the risk of using the RP without such alternation or switch." Yet, none of the biosimilars have received this designation (36). These biosimilars may become substitutes of brand biological agents. Furthermore, along with the similarity to $\mathrm{ADL}$ and its lower price, biosimilars have the opportunity to make biologic treatment for RA more widely available. At the moment, however, this goal has not been achieved due to a number of reasons such as high prices, for example $(37,38)$. An important limitation of this review is the relative lack of real-life studies of the contrast between ADL and its biosimilars. More extensive and in-depth real-life research is required to allow for biosimilars to become available.

The immunogenicity of biologics that can lead to the occurrence of ADAs and nAbs in patients, and therefore affect PK, alter clinical safety and efficacy profiles, and is an important consideration of biosimilar studies (39). We reviewed several possible factors that may confound the results of immunogenicity and noticed some limitations in the assessment of immunogenicity. First, concomitant medication may affect the incidence of ADAs and nAbs. In the phase III trials of all seven biosimilar studies presented in this review, patients used MTX while being treated with biologics, but the combination of MTX and biologics can lead to therapeutic protein-drug interactions, which can then reduce the incidence of ADAs and improve efficacy $(40,41)$. Second, most of the trials allowed patients to be treated with $<2$ biologic therapies (such as etanercept, infliximab) other than ADL and its biosimilars prior to the start of the trial, which may have a potential impact on the incidence of ADAs and nAbs. Third, the incidence of ADAs and nAbs increased with the duration of treatment. Furthermore, an ECL assay that has high sensitivity, and a broad dynamic range was used to detect the ADAs status in all trials, however, most of them did not consider the steps (such as acid dissociation pretreatment) to disrupt circulating ADAs/nAbs-drug complexes, which may underestimate the incidence of $\mathrm{ADA}$-positivity in each arm and ADA titer. In addition, it may be affected by the matrix effect in the test sample. In terms of the detection of nAbs, cell-based assays, which can test multiple functional domains and better mimic the mechanisms by which nAbs work their effect in living biological systems, are generally the preferred method (42).

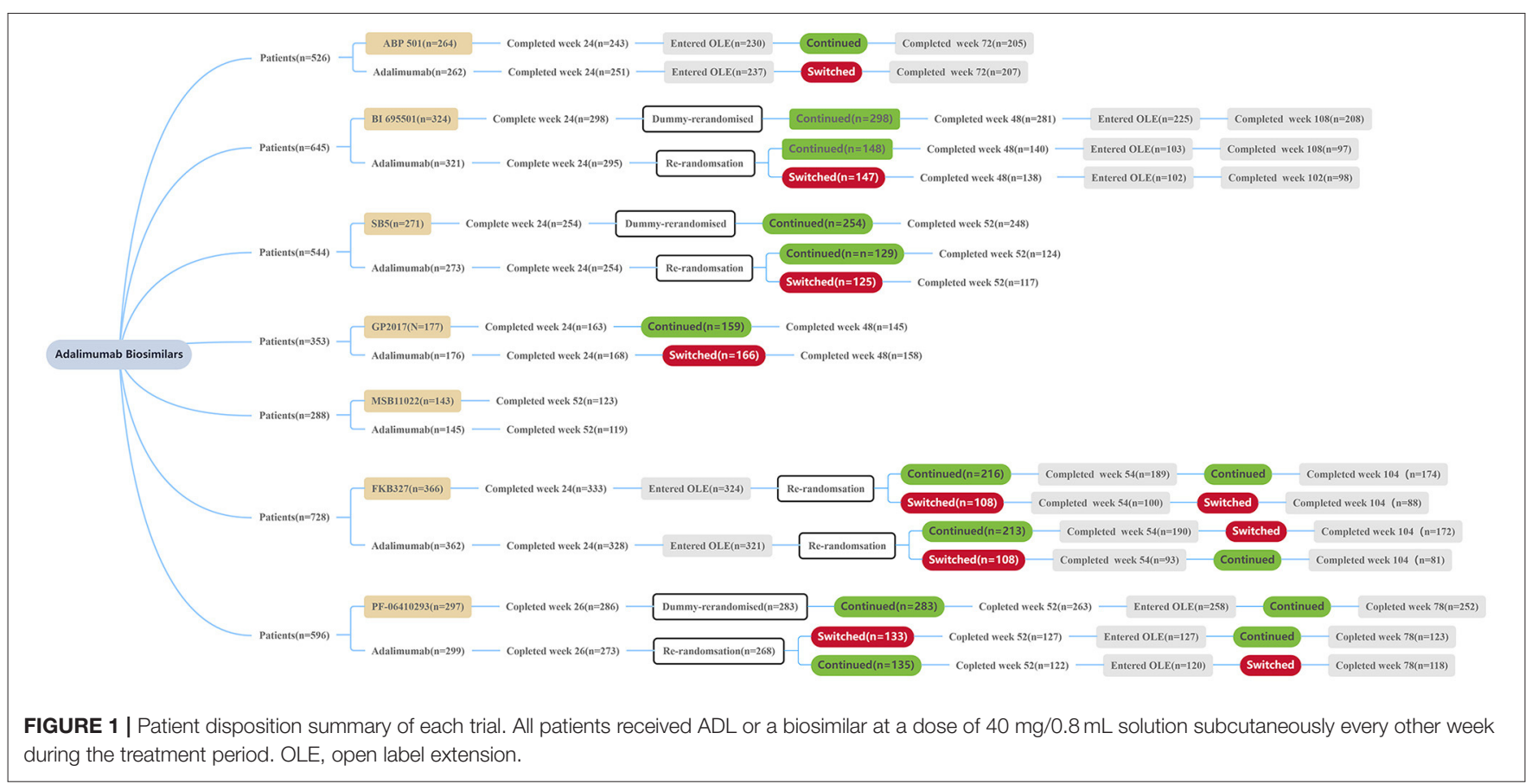


But the cell-based assays were only used in the trials of ABP501, BI 695501, and PF-06412393.

\section{CONCLUSION}

Based on the pivotal trials of the seven biosimilars, all of them showed comparable efficacy, safety, and immunogenicity to ADL. Subtle differences are considered to be due to some methodological bias, rather than the properties of biosimilars, however, several limitations in immunogenicity assessment are of concern. For the biologic-naive patients, biosimilars may be chosen for the first biologic therapy of RA. Second, all

\section{REFERENCES}

1. Aletaha D, Smolen JS. Diagnosis and management of rheumatoid arthritis: a review. JAMA. (2018) 320:1360-72. doi: 10.1001/jama.2018.13103

2. Curtis JR, Singh JA. Use of biologics in rheumatoid arthritis: current and emerging paradigms of care. Clin. Ther. (2011) 33:679-707. doi: 10.1016/j.clinthera.2011.05.044

3. Blüml S, Scheinecker C, Smolen JS, Redlich K. Targeting TNF receptors in rheumatoid arthritis. Int. Immunol. (2012) 24:275-81. doi: 10.1093/intimm/dxs047

4. Di Giovine FS, Nuki G, Duff GW. Tumour necrosis factor in synovial exudates. Ann. Rheum. Dis. (1988) 47:768-72. doi: 10.1136/ard.47.9.768

5. Tracey D, Klareskog L, Sasso EH, Salfeld JG, Tak PP. Tumor necrosis factor antagonist mechanisms of action: a comprehensive review. Pharmacol. Ther. (2008) 117:244-79. doi: 10.1016/j.pharmthera.2007.10.001

6. Van De Putte LBA, Atkins C, Malaise M, Sany J, Russell AS, et al. Efficacy and safety of adalimumab as monotherapy in patients with rheumatoid arthritis for whom previous disease modifying antirheumatic drug treatment has failed. Ann. Rheum. Dis. (2004) 63:508-16. doi: 10.1136/ard.2003.013052

7. Lundkvist J, Kastäng F, Kobelt G. The burden of rheumatoid arthritis and access to treatment: health burden and costs. Eur. J. Health Econ. (2008) 8:49-60. doi: 10.1007/s10198-007-0088-8

8. Dörner T, Strand V, Castañeda-Hernández G, Ferraccioli G, Isaacs JD, Kvien TK, et al. The role of biosimilars in the treatment of rheumatic diseases. Ann. Rheum. Dis. (2013) 72:322-8. doi: 10.1136/annrheumdis-2012-202715

9. Ishii-Watabe A, Kuwabara T. Biosimilarity assessment of biosimilar therapeutic monoclonal antibodies. Drug Metab. Pharmacokinet. (2019) 34:64-70. doi: 10.1016/j.dmpk.2018.11.004

10. Velayudhan J, Chen Y, Rohrbach A, Pastula C, Maher G, Thomas H, et al. Demonstration of functional similarity of proposed biosimilar ABP 501 to adalimumab. BioDrugs. (2016) 30:339-51. doi: 10.1007/s40259-016-0185-2

11. Liu J, Eris T, Li C, Cao S, Kuhns S. Assessing analytical similarity of proposed amgen biosimilar ABP 501 to adalimumab. BioDrugs. (2016) 30:321-38. doi: 10.1007/s40259-016-0184-3

12. Kaur P, Chow V, Zhang N, Moxness M, Kaliyaperumal A, Markus R. A randomised, single-blind, single-dose, three-arm, parallel-group study in healthy subjects to demonstrate pharmacokinetic equivalence of ABP 501 and adalimumab. Ann. Rheum. Dis. (2017) 76:526-33. doi: 10.1136/annrheumdis-2015-208914

13. Cohen S, Genovese MC, Choy E, Perez-Ruiz F, Matsumoto A, Pavelka K, et al. Efficacy and safety of the biosimilar ABP 501 compared with adalimumab in patients with moderate to severe rheumatoid arthritis: a randomised, doubleblind, phase III equivalence study. Ann. Rheum. Dis. (2017) 76:1679-87. doi: 10.1136/annrheumdis-2016-210459

14. Cohen S, Pablos JL, Pavelka K, Müller GA, Matsumoto A, Kivitz A, et al. An open-label extension study to demonstrate long-term safety and efficacy of ABP 501 in patients with rheumatoid arthritis. Arthritis Res. Ther. (2019) 21:1-10. doi: 10.1186/s13075-019-1857-3

15. Cohen SB, Czeloth N, Lee E, Klimiuk PA, Peter N, Jayadeva G. Longterm safety, efficacy, and immunogenicity of adalimumab biosimilar BI biosimilar studies conducted research on the transition from ADL to biosimilars. The results of these studies have shown that switching from ADL to a biosimilar does not have a significant impact on efficacy, safety, and immunogenicity.

\section{AUTHOR CONTRIBUTIONS}

ZS and RH contributed to the conception and design of the study. RH, LP, ML, and XL searched the database and extract data. ZS, ML, and LP made tables. ML and XL made figures. $\mathrm{RH}, \mathrm{ZS}$, and XL wrote the first draft of the manuscript. All authors contributed to manuscript revision, read, and approved the submitted version.

695501 and adalimumab reference product in patients with moderatelyto-severely active rheumatoid arthritis: results from a phase $3 \mathrm{~b}$ extension study (VOLTAIRE-RAext). Expert Opin. Biol. Ther. (2019) 19:1097-105. doi: 10.1080/14712598.2019.1645114

16. Cohen SB, Alonso-Ruiz A, Klimiuk PA, Lee EC, Peter N, Sonderegger I, Assudani D. Similar efficacy, safety and immunogenicity of adalimumab biosimilar BI 695501 and Humira reference product in patients with moderately to severely active rheumatoid arthritis: results from the phase III randomised VOLTAIRE-RA equivalence study. Ann. Rheum. Dis. (2018) 77:914-21. doi: 10.1136/annrheumdis-2017-212245

17. Weinblatt ME, Baranauskaite A, Niebrzydowski J, Dokoupilova E, Zielinska A, Jaworski J, et al. Phase III randomized study of SB5, an adalimumab biosimilar, versus reference adalimumab in patients with moderateto-severe rheumatoid arthritis. Arthritis Rheumatol. (2018) 70:40-8. doi: 10.1002/art.40336

18. Bruni C, Bitti R, Nacci F, Cometi L, Tofani L, Bartoli F, et al. Efficacy and safety of switching from reference adalimumab to SB5 in a real-life cohort of inflammatory rheumatic joint diseases. Clin. Rheumatol. (2020) 40:85-91. doi: 10.1007/s10067-020-05199-w

19. Weinblatt ME, Baranauskaite A, Dokoupilova E, Zielinska A, Jaworski J, Racewicz A, et al. Switching from reference adalimumab to SB5 (adalimumab biosimilar) in patients with rheumatoid arthritis: fifty-twoweek phase iii randomized study results. Arthritis Rheumatol. (2018) 70:83240. doi: 10.1002/art.40444

20. Kronthaler U, Fritsch C, Hainzl O, Seidl A, da Silva A. Comparative functional and pharmacological characterization of Sandoz proposed biosimilar adalimumab (GP2017): rationale for extrapolation across indications. Expert Opin. Biol. Ther. (2018) 18:921-30. doi: 10.1080/14712598.2018.14 95193

21. von Richter O, Lemke L, Haliduola H, Fuhr R, Koernicke T, Schuck E, et al. GP2017, an adalimumab biosimilar: pharmacokinetic similarity to its reference medicine and pharmacokinetics comparison of different administration methods. Expert Opin. Biol. Ther. (2019) 19:1075-83. doi: 10.1080/14712598.2019.1571580

22. Wiland P, Jeka S, Dokoupilová E, Brandt-Jürgens J, Miranda Limón JM, Cantalejo Moreira M, Cabello RV, et al. Switching to biosimilar SDZADL in patients with moderate-to-severe active rheumatoid arthritis: 48week efficacy, safety and immunogenicity results from the phase III, randomized, double-blind admyra study. BioDrugs. (2020) 34:809-23. doi: 10.1007/s40259-020-00447-6

23. Wiland P, Jeka S, Dokoupilová E, Miranda Limón JM, Jauch-Lembach J, Thakur A, et al. A randomized, double-blind, parallel-group, multicenter study to compare the efficacy, safety and immunogenicity of a proposed adalimumab biosimilar (GP2017) with reference adalimumab in patients with moderate-to-severe active rheumatoid arthritis [abstract]. Arthritis Rheumatol. (2018) 70 (Suppl. 10). https://acrabstracts.org/abstract/arandomized-double-blind-parallel-group-multicenter-study-to-comparethe-efficacy-safety-and-immunogenicity-of-a-proposed-adalimumabbiosimilar-gp2017-with-reference-adalimumab-in-patients-with/ (accessed December 5, 2020). 
24. Magnenat L, Palmese A, Fremaux C, D’Amici F, Terlizzese M. Demonstration of physicochemical and functional similarity between the proposed biosimilar adalimumab MSB11022 and Humira $®$ Laurent. MAbs. (2011) 44:1689-99. doi: 10.1080/19420862.2016.1259046

25. Hyland E, Mant T, Vlachos P, Attkins N, Ullmann M, Roy S, et al. Comparison of the pharmacokinetics, safety, and immunogenicity of MSB11022, a biosimilar of adalimumab, with Humira $($ in healthy subjects. Br. J. Clin. Pharmacol. (2016) 82:983-93. doi: 10.1111/bcp.13039

26. Edwards CJ, Monnet J, Ullmann M, Vlachos P, Chyrok V, Ghori V. Safety of adalimumab biosimilar MSB11022 (acetate-buffered formulation) in patients with moderately-to-severely active rheumatoid arthritis. Clin. Rheumatol. (2019) 38:3381-90. doi: 10.1007/s10067-019-04679-y

27. Hercogová J, Papp KA, Chyrok V, Ullmann M, Vlachos P, Edwards CJ. AURIEL-PsO: a randomized, double-blind phase III equivalence trial to demonstrate the clinical similarity of the proposed biosimilar MSB11022 to reference adalimumab in patients with moderate-to-severe chronic plaque-type psoriasis. Br. J. Dermatol. (2020) 182:316-26. doi: 10.1111/bjd. 18220

28. Puri A, Niewiarowski A, Arai Y, Nomura H, Baird M, Dalrymple I, et al. Pharmacokinetics, safety, tolerability and immunogenicity of FKB327, a new biosimilar medicine of adalimumab/Humira, in healthy subjects. Br. J. Clin. Pharmacol. (2017) 83:1405-15. doi: 10.1111/bcp.13245

29. Genovese MC, Glover J, Greenwald M, Porawska W, El Khouri EC, Dokoupilova E, et al. FKB327, an adalimumab biosimilar, versus the reference product: results of a randomized, phase III, double-blind study, and its open-label extension. Arthritis Res. Ther. (2019) 21:1-12. doi: 10.1186/s13075-019-2046-0

30. Genovese MC, Kellner H, Arai Y, Muniz R, Alten R. Long-term safety, immunogenicity and efficacy comparing FKB327 with the adalimumab reference product in patients with active rheumatoid arthritis: data from randomised double-blind and open-label extension studies. RMD Open. (2020) 6:e000987. doi: 10.1136/rmdopen-2019-000987

31. Derzi M, Shoieb AM, Ripp SL, Finch GL, Lorello LG, O’Neil SP, et al. Comparative nonclinical assessments of the biosimilar PF-06410293 and originator adalimumab. Regul. Toxicol. Pharmacol. (2020) 112:104587. doi: 10.1016/j.yrtph.2020.104587

32. ClinicalTrials.gov. A Study of PF-06410293 (adalimumab-Pfizer) and ADALIMUMAB (HUMIRA) in Healthy Subjects (REFLECTIONS B538-07) (B538-07). (2014) (last update: 13 April 2015). Available online at: https:// clinicaltrials.gov/ct2/show/NCT02237729 (accessed October 5, 2020).

33. Fleischmann RM, Alten R, Pileckyte M, Lobello K, Hua SY, Cronenberger C, et al. A comparative clinical study of PF-06410293, a candidate adalimumab biosimilar, and adalimumab reference product (Humira $($ ) in the treatment of active rheumatoid arthritis. Arthritis Res. Ther. (2018) 20:112. doi: 10.1186/s13075-018-1676-y

34. Fleischmann R, Alvarez D, Bock A, Cronenberger C, Vranic I, Zhang W, et al. Efcacy, safety and immunogenicity in patients with rheumatoid arthritis comparing PF-06410293 (ADL-PF), an adalimumab (ADL) biosimilar, and reference ADL: results from week 26-52 of a double-blind, randomised phase 3 study including patients who switched from ADL-PF to reference ADL at week 26 [abstract no. AB0289]. Ann. Rheum. Dis. (2020) 79(Suppl. 1):1439. doi: 10.1136/annrheumdis-2020-eular.279

35. McKinnon RA, Cook M, Liauw W, Marabani M, Marschner IC, Packer $\mathrm{NH}$, et al. Biosimilarity and Interchangeability: principles and evidence: a systematic review. BioDrugs. (2018) 32:27-52. doi: 10.1007/s40259-017-0256-Z

36. U.S. Department of Health and Human Services, Food and Drug Administration (FDA), Center for Drug Evaluation and Research (CDER), Center for Biologics Evaluation and Research (CBER). Considerations in Demonstrating Interchangeability With a Reference Product-Guidance for Industry. Fda (2019) 23.

37. Chen BK, Yang YT, Bennett CL. Why biologics and biosimilars remain so expensive: despite two wins for biosimilars, the supreme court's recent rulings do not solve fundamental barriers to competition. Drugs. (2018) 78:1777-81. doi: 10.1007/s40265-018-1009-0

38. Zhai MZ, Sarpatwari A, Kesselheim AS. Why are biosimilars not living up to their promise in the US? AMA J. Ethics. (2019) 21:668-78. doi: 10.1001/amajethics.2019.668

39. Shankar G, Arkin S, Cocea L, Devanarayan V, Kirshner S, Kromminga A, American Association of Pharmaceutical Scientists, et al. Assessment and reporting of the clinical immunogenicity of therapeutic proteins and peptidesharmonized terminology and tactical recommendations. AAPS J. (2014) 16:658-73. doi: 10.1208/s12248-014-9599-2

40. Krieckaert CL, Nurmohamed MT, Wolbink GJ. Methotrexate reduces immunogenicity in adalimumab treated rheumatoid arthritis patients in a dose dependent manner. Ann. Rheum. Dis. (2012) 71:1914-5. doi: 10.1136/annrheumdis-2012-201544

41. van Schouwenburg PA, Rispens T, Wolbink GJ. Immunogenicity of antiTNF biologic therapies for rheumatoid arthritis. Nat. Rev. Rheumatol. (2013) 9:164-72. doi: 10.1038/nrrheum.2013.4

42. Gorovits B, Fiscella M, Havert M, Koren E, Long B, Milton M, Purushothama S. Recommendations for the development of cell-based anti-viral vector neutralizing antibody assays. AAPS J. (2020) 22:24. doi: 10.1208/s12248-019-0403-1

Conflict of Interest: The authors declare that the research was conducted in the absence of any commercial or financial relationships that could be construed as a potential conflict of interest.

Copyright (c) $2021 \mathrm{Lu}, \mathrm{Hu}$, Peng, Liu and Sun. This is an open-access article distributed under the terms of the Creative Commons Attribution License (CC BY). The use, distribution or reproduction in other forums is permitted, provided the original author(s) and the copyright owner(s) are credited and that the original publication in this journal is cited, in accordance with accepted academic practice. No use, distribution or reproduction is permitted which does not comply with these terms. 